\title{
Proline-Functionalised Calix[4]arene: An Anion-Triggered Hydrogelator
}

\author{
Thomas Becker, ${ }^{a}$ Ching Yong Goh, ${ }^{a}$ Franca Jones, ${ }^{a}$ Matthew J. McIldowie, ${ }^{a}$ Mauro Mocerino ${ }^{a}$ and Mark \\ I. Ogden ${ }^{a}$
}

Received (in XXX, XXX) 1st January 2007, Accepted 1st January 2007

First published on the web 1st January 2007

5 DOI: 10.1039/b000000x

A water-soluble, chiral calix[4]arene has been found to form hydrogels when triggered by the presence of specific anions, with efficacy linked to the Hofmeister series; the gel properties are modified by the associated cations, and gelation can be reversibly ${ }_{10}$ switched off by increasing $\mathbf{p H}$.

Low molecular weight hydrogelators have received significant attention recently. ${ }^{1-3}$ The range of possible applications drives much of this effort; stimuli responsive gels are of particular interest for applications such as drug-release formulations and 15 sensors, with low molecular weight gelators having some advantages in terms of potential applications compared to the much more common polymeric gelators. Gelators responsive to light, heat, and chemical environment have been reported. ${ }^{4-}$

7 Despite this activity, molecular hydrogelators are not 20 common, and the range of stimuli responsive systems known is very limited. Macrocyclic hydrogelators appear to be limited to an iminodiacetate resorcinarene, ${ }^{8}$ and the very recently reported behaviour of cucurbit[7]uril, ${ }^{9}$ and a modified $\beta$-cyclodextrin ${ }^{10,}{ }^{11}$. Gelation of the resorcinarene and 25 cucurbituril occurs at acidic $\mathrm{pH}(<2.5)$, and is switched off with addition of metal cations that bind to the macrocycle. The cyclodextrin system is based on covalent attachment of a guest moiety leading to self-inclusion resulting in gelation. Addition of a guest results in a gel-sol transformation. In 30 contrast, the proline-functionalised calix[4]arene $\mathbf{1}$ reported here acts as a hydrogelator only in the presence of specific anions, with fine-tuning of the gel properties induced by varying the associated cation. In addition, the gels are stable over a $\mathrm{pH}$ range of $0-7$, and are reversibly disassembled by 35 increasing the $\mathrm{pH}$ above $\sim 7$.

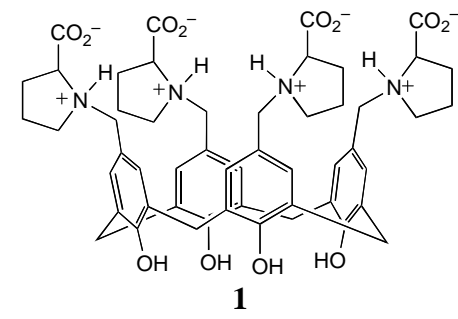

Proline is added to the upper rim of calix[4]arene in a single step by reaction with formaldehyde in acetic acid, using 40 methodologies similar to those reported previously for reaction of calixarenes, formaldehyde and secondary amines. $^{12,13} \dagger$

The proline functionalised calixarene is significantly water soluble (up to $\sim 500 \mathrm{~g} \mathrm{~L}^{-1}$ ). The resonances in the ${ }^{1} \mathrm{H}$ NMR 45 spectrum broaden significantly as concentration increases, suggesting that molecular assemblies are forming. A critical concentration of $5.6 \mathrm{mM}$ was determined by monitoring the absorbance of Rhodamine 6G as a function of calixarene concentration (Fig S1). ${ }^{14}$ Gel formation was not observed at 50 any accessible concentration in experiments with solutions of 1 alone.

While studying the interaction of $\mathbf{1}$ with cations in aqueous solution, gel formation was observed upon the addition of lithium chloride to the solution. Upon investigation of this 55 phenomenon, it was found that the gel formation was most dependent on the anion added to the solution, with variations in the cation having a lesser but notable impact. Gel formation was most facile with nitrate anions, with bromide and chloride also successful with specific cations. Where gelation failed, 60 the mixture either remained as a solution, or formed a transient gel, which subsequently transformed to a microcrystalline needle- or plate-like precipitate. Control experiments with proline at equivalent concentrations did not form gels. Table 1 provides an overview of the results 65 obtained to date; Fig. 1 shows some images of the products.

Table 1 Results of hydrogel formation experiments for a $0.4 \mathrm{~mol} \mathrm{~L}^{-1}$ solution of $\mathbf{1}$ in the presence of different electrolytes.

$\begin{array}{cccc}\text { Cation } & \text { Anion } & \text { [Salt] }\left(\mathrm{mol} \mathrm{L}^{-1}\right) & \text { Result } \\ \mathrm{Na}^{+} & \mathrm{SO}_{4}{ }^{2-} & 0.10 & \mathrm{~L} \\ \mathrm{Na}^{+} & \mathrm{Cl}^{-} & 0.10 & \mathrm{~L} \\ \mathrm{Na}^{+} & \mathrm{NO}_{3}^{-} & 0.10 & \mathrm{G} \\ \mathrm{Na}^{+} & \mathrm{Br}^{-} & 0.10 & \mathrm{G} \\ \mathrm{Na}^{+} & \mathrm{I}^{-} & 0.10 & \mathrm{TG}(14) \\ \mathrm{Na}^{+} & \mathrm{ClO}_{4}^{-} & 0.10 & \mathrm{TG}(0) \\ \mathrm{H}^{+} & \mathrm{SO}_{4}{ }^{+} & 0.05 & \mathrm{C} \\ \mathrm{H}^{+} & \mathrm{Cl}^{-} & 0.05 & \mathrm{~L} \\ \mathrm{H}^{+} & \mathrm{Br}^{-} & 0.05 & \mathrm{G} \\ \mathrm{H}^{+} & \mathrm{NO}_{3}{ }^{-} & 0.05 & \mathrm{G} \\ \mathrm{H}^{+} & \mathrm{ClO}_{4}^{-} & 0.05 & \mathrm{TG}(0) \\ \mathrm{Li}^{+} & \mathrm{Cl}^{-} & 1.26 & \mathrm{G} \\ \mathrm{Na}^{+} & \mathrm{Cl}^{-} & 1.26 & \mathrm{IG} \\ \mathrm{Mg}^{2+} & \mathrm{Cl}^{-} & 0.04 & \mathrm{G} \\ \mathrm{Ca}^{2+} & \mathrm{Cl}^{-} & 1.25 & \mathrm{C} \\ \mathrm{La}^{3+} & \mathrm{Cl}^{-} & 0.05 & \mathrm{~L} \\ \mathrm{Li}^{+} & \mathrm{NO}_{3}^{-} & 0.12 & \mathrm{G} \\ \mathrm{Ca}^{2+} & \mathrm{NO}_{3}{ }^{-} & 0.05 & \mathrm{G} \\ \mathrm{Mn}^{2+} & \mathrm{NO}_{3}^{-} & 0.05 & \mathrm{G} \\ \mathrm{La}^{3+} & \mathrm{NO}_{3}^{-} & 0.05 & \mathrm{G} \\ \mathrm{La}^{3+} & \mathrm{NO}_{3}{ }^{-} & 0.01 & \mathrm{G} \\ \mathrm{La}^{3+} & \mathrm{NO}_{3}^{-} & 0.007 & \mathrm{IG} / \mathrm{TG}(2)\end{array}$

${ }^{a} \mathrm{G}=$ stable gel (at least 7 days), $\mathrm{TG}(\mathrm{X})=$ transient gel (followed by crystallisation commencing after $\sim \mathrm{X}$ hours), IG = incomplete gelation 70 (not stable to inversion), $\mathrm{L}=$ liquid, $\mathrm{C}=$ crystallisation 
(a)

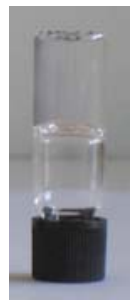

(b)

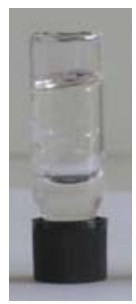

(c)

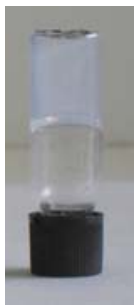

(d)

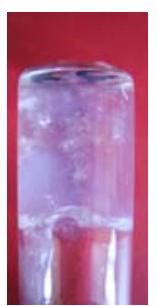

Fig. 1 Images of products formed with $0.4 \mathrm{~mol} \mathrm{~L}^{-1}$ solutions of $\mathbf{1}$, and salts. (a) LiCl. $1.26 \mathrm{~mol} \mathrm{~L}^{-1}$, stable gel, (b) $\mathrm{NaCl}, 1.26 \mathrm{~mol} \mathrm{~L}^{-1}$, incomplete gel, (c) $\mathrm{La}\left(\mathrm{NO}_{3}\right)_{3}, 0.01 \mathrm{~mol} \mathrm{~L}^{-1}$, stable translucent gel, and (d) NaI, 0.10 mol L ${ }^{-1}$, transient gel (crystallisation has commenced in this image).

(a)

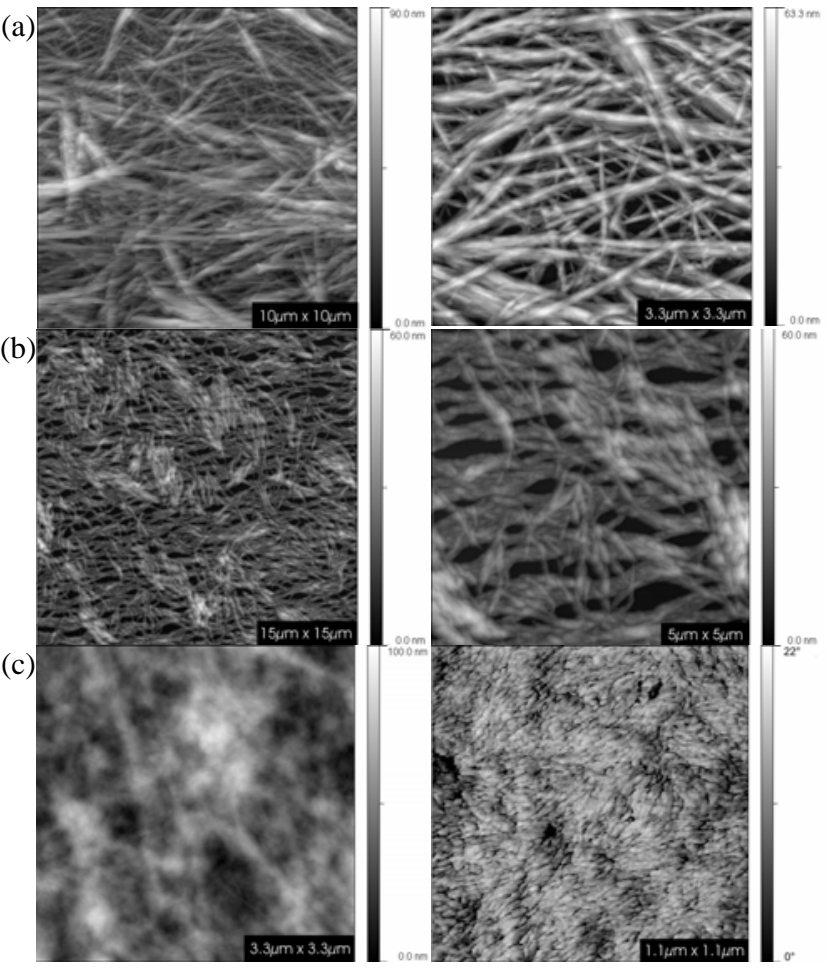

5 Fig. 2 Atomic force micrographs of hydrogels deposited as thin films on mica and imaged immediately, formed from $\mathbf{1}$ and (a) $\mathrm{MgCl}_{2}$, (b) $\mathrm{Mn}\left(\mathrm{NO}_{3}\right)_{2}$, and (c) $\mathrm{La}\left(\mathrm{NO}_{3}\right)_{3}$. All images show topography aside from the bottom right image which is phase contrast, to better reveal the internal structure.

10 Characterisation of the gels was achieved using atomic force microscopy; a thin film of the wet gel was placed on freshly cleaved mica, and imaged in tapping mode. A fibrous network structure was clearly observed (Fig. 2), the density of which depended on the particular electrolyte; the denser 15 networks correlated qualitatively with the more robust hydrogels. Phase imaging was required to discern the structure of the denser gels (Fig. 2(c)), and also enabled imaging of the needle-like crystals formed as a gel collapsed on the mica substrate (Fig. S2), supporting observations of the bulk ${ }_{20}$ systems, which were observed to transform from gel to a crystalline precipitate in some cases. The smallest fibres that could be measured in cross section were $7 \mathrm{~nm}$ in diameter for the $\mathrm{MgCl}_{2}$ based gel (Fig. S3), suggesting the assemblies are not linear assemblies of single molecules, although this
${ }_{25}$ possibility cannot be completely ruled out, as the smallest measurable fibres may be linear agglomerates of smaller units.

Our initial hypothesis was that the gel formation was related to selective binding of the anion or ion pair by the calixarene. Anion binding has been reported to inhibit gel ${ }_{30}$ formation as a result of specific binding interactions. ${ }^{15,}{ }^{16}{ }^{1} \mathrm{H}$ NMR spectra were, however, not significantly perturbed by the addition of any of the salts. The fact that the anion effect was found to be much stronger than the influence of cations led us to consider the Hofmeister or specific ion effect, which 35 typically behaves in this way. ${ }^{17,}{ }^{18}$ The typical Hofmeister series is:

$$
\mathrm{I}^{-}<\mathrm{ClO}_{4}^{-}<\mathrm{NO}_{3}^{-}<\mathrm{Br}^{-}<\mathrm{Cl}^{-}<\mathrm{SO}_{4}{ }^{2-}
$$

Strongly hydrated anions (to the right) are referred to as salting-out or kosmotropic ions, and the less hydrated anions 40 are salting-in or chaotropic ions. Ion specificity of electrolytes has been found to apply in many areas of polymer, colloid and interface science, although the origin of the effect remains an active area of investigation. ${ }^{19,}{ }^{20}$ In the present case, it appears that the tendency to form gels increases from right to left 45 across the series, with the kosmotropic ions resulting in a liquid phase, whereas the more chaotropic ions tend to induce gelation. Superimposed on this trend is crystallisation of the mixture, which is presumably driven by factors such as solubility and lattice energy. Thus, the strongly chaotropic 50 ions, which are less hydrated, do form gels but this is followed by crystallisation and collapse of the gel. Between these extremes is a range where a more stable hydrogel is formed. The series of sodium salts studied illustrates this trend (Table 1). The kinetic stability with respect to 55 crystallisation varies as a function of the cation present and the salt concentration. Redetermination of the critical concentration for aggregation in the presence of electrolytes indicated that aggregation is occurring before gelation takes place, suggesting that the electrolytes influence further ${ }_{60}$ agglomeration of the units that are spontaneously formed in the presence and absence of added electrolyte (Fig. S1). The gelation induced by acids is notable (Table 1), given that low $\mathrm{pH}$ was required to activate two of the previously reported macrocyclic hydrogelators mentioned above. While the ${ }_{65}$ previous work reported no selectivity as a function of the acid used, here a stable hydrogel is only formed upon addition of nitric or hydrobromic acids. Modification of the anioninduced gelation can be achieved by altering the electrolyte cation or total concentration. This is illustrated by the results 70 obtained with the series of chloride and nitrate salts reported in the lower section of Table 1.

Amino acid surfactants have been reported to form hydrogels, although at intermediate $\mathrm{pH}$ values where partial deprotonation of the carboxylic acid groups is proposed to be 75 important. ${ }^{1,21}$ The behaviour of $\mathbf{1}$ is different in that gelation occurs over a $\mathrm{pH}$ range of approximately $0-7$, but fails at higher $\mathrm{pH}$ values, suggesting that protonation of the tertiary amine groups is the key structural requirement, and the protonation state of the carboxylic group is not significant. ${ }_{80}$ Protonation of amino acid esters of cholesterol has been shown to trigger gelation, although no anion specific behaviour was reported. ${ }^{5}$ 
Hofmeister effects are well known in polymeric systems, and are reported to change the temperature of transition in surfactant-based coagels for example. ${ }^{22}$ Specific ion accumulation on microgel particles has also recently been

5 reported as a means to study the origins of Hofmeister effects. $^{23}$ To our knowledge, however, a sol-gel transition induced by a specific ion effect appears to be a new observation, and is particularly notable in a low molecular weight system. It is possible that such effects have been 10 overlooked in previous work, since the impact of factors such as ionic strength, for example, is often tested with only a single electrolyte. The results reported here suggest that greater control of hydrogel formation may be achieved by considering specific ion effects, even with low molecular 15 weight hydrogelators. Work is underway to probe the physicochemical properties of $\mathbf{1}$ in more detail, and to extend these studies to other calixarene and amino acid derivatives.

\section{Notes and references}

${ }^{a}$ Nanochemistry Research Institute, Dept of Applied Chemistry, Curtin 20 University of Technology, GPO Box U 1987, Perth, Australia 6845. Fax: +618 9266 4699; Tel: +6189266 3838; E-mail: m.mocerino@curtin.edu.au,m.ogden@curtin.edu.au

† Electronic Supplementary Information (ESI) available: Synthesis and characterisation of $\mathbf{1}$, solution aggregation results, and atomic force 25 microscopy methods and additional images. See http://dx.doi.org/10.1039/b000000x/

1. L. A. Estroff and A. D. Hamilton, Chem. Rev., 2004, 104, 1201-1217.

2. N. M. Sangeetha and U. Maitra, Chem. Soc. Rev., 2005, 34, 821-836.

3. M. de Loos, B. L. Feringa and J. H. van Esch, Eur. J. Org. Chem., 2005, 3615-3631.

4. A. Meister, M. Bastrop, S. Koschoreck, V. M. Garamus, T. Sinemus, G. Hempel, S. Drescher, B. Dobner, W. Richtering, K. Huber and A. Blume, Langmuir, 2007, 23, 7715-7723.

5. Y. G. Li, K. Q. Liu, J. Liu, J. X. Peng, X. L. Feng and Y. Fang, Langmuir, 2006, 22, 7016-7020.

6. A. Garcia, M. Marquez, T. Cai, R. Rosario, Z. B. Hu, D. Gust, M. Hayes, S. A. Vail and C. D. Park, Langmuir, 2007, 23, 224-229.

7. Y. F. Zhou, M. Xu, T. Yi, S. Z. Xiao, Z. G. Zhou, F. Y. Li and C. H. Huang, Langmuir, 2007, 23, 202-208.

40 8. S. R. Haines and R. G. Harrison, Chem. Commun., 2002, 2846-2847.

9. I. Hwang, W. S. Jeon, H. J. Kim, D. Kim, H. Kim, N. Selvapalam, N. Fujita, S. Shinkai and K. Kim, Angew. Chem. Int. Ed., 2007, 46, $210-$ 213.

10. W. Deng, H. Yamaguchi, Y. Takashima and A. Harada, Angew. Chem. Int. Ed., 2007, 46, 5144-5147.

11. W. Deng, H. Yamaguchi, Y. Takashima and A. Harada, Chem. Asian J., 2008, 3, 687-695.

12. C. D. Gutsche and K. C. Nam, J. Am. Chem. Soc., 1988, 110, 61536162.

50 13. U. Schneider and H. J. Schneider, Chem. Ber., 1994, 127, 2455-2469.

14. H. M. Willemen, T. Vermonden, A. Koudijs, A. T. M. Marcelis and E. J. R. Sudholter, Colloids Surf., A, 2003, 218, 59-64.

15. C. E. Stanley, N. Clarke, K. M. Anderson, J. A. Elder, J. T. Lenthall and J. W. Steed, Chem. Commun., 2006, 3199-3201.

55 16. J. E. A. Webb, M. J. Crossley, P. Turner and P. Thordarson, J. Am. Chem. Soc., 2007, 129, 7155-7162.

17. M. G. Cacace, E. M. Landau and J. J. Ramsden, Quarterly Reviews of Biophysics, 1997, 30, 241-277.

18. W. Kunz, Pure Appl. Chem., 2006, 78, 1611-1617.

60 19. X. Chen, T. Yang, S. Kataoka and P. S. Cremer, J. Am. Chem. Soc., 2007, 129, 12272-12279.

20. A. S. Thomas and A. H. Elcock, J. Am. Chem. Soc., 2007, 129, 14887-14898.

21. T. Imae, N. Hayashi, T. Matsumoto, T. Tada and M. Furusaka, J. 65 Colloid Interface Sci., 2000, 225, 285-290.
22. P. Lo Nostro, B. W. Ninham, M. Ambrosi, L. Fratoni, S. Palma, D. Allemandi and P. Baglioni, Langmuir, 2003, 19, 9583-9591.

23. T. Lopez-Leon, A. Elaissari, J. L. Ortega-Vinuesa and D. BastosGonzalez, Chemphyschem, 2007, 8, 148-156.
70 